\title{
A Study on Translation of Chinese Cuisine from its Metaphors and Culture
}

\author{
Ming Cai \\ Xinyang Agriculture and Forestry University \\ School of Foreign Languages, Xinyang Agriculture and Forestry University, Xinyang, China \\ 329495213@qq.com
}

Keywords: Chinese Culture, Chinese Cuisine, Translation, Metaphor

Abstract: This essay discusses the translation of Chinese cuisine from the standards and usual ways of menu translation and then draws the attention especially to the metaphor-loaded and culture-loaded food names according to the naming principles and cultural backgrounds. At last, it gives a general view to the principles for the translation of Chinese cuisine.

\section{Introduction}

Nowadays, with the economic power of China is growing stronger and stronger, China has played an increasingly important role on the global stage. More and more people from other countries want to have a better understanding of China. So, to introduce the culture of Chinese cuisine to the coming visitors and the outside world is an important task.

In western people's eyes, Chinese food is a great wonder of collection of cooking skills. And they are often attracted to the looks, shapes and designs of Chinese food besides their delicious aroma and taste. While the sights of Chinese food bring pleasure, the name of dishes also capture close attention of foreign people. When people from different cultural background enjoy Chinese food, they are often curious and eager to know the exact meaning of the name of certain food. They are also interested in its origins.

Compared with western food names, Chinese dish names are quite unique because there are plenty of metaphor-loaded food names which are characteristically related to cultural factors. The study of Chinese cuisine translation as an academic field is a relatively new area in China as well as in the West. Chinese dish names, as a window of Chinese food culture is actually an effective means to inform foreigners of China's special cultural environment. Therefore, Chinese food names are highly worthy of being translated. It is obvious that successful translation of them serves as a bridge for the communication between China and other countries.

\section{Translation of Chinese Cuisine}

In order to make a deeply analysis on the translation of Chinese cuisine as well as a better understanding of the translation methods, we should first get to know the standards of menu translation. Then we will begin our exploration in the translation of Chinese Cuisine. 


\subsection{Standards of Menu Translation}

To achieve accurate menu translation from Chinese to English, the most important thing is to have certain overriding guiding principles or standards in this regard. Strictly speaking, a translation theory in its true sense in China originated from Yan $\mathrm{Fu}$ (严复). He proposed the famous triple principle for translation, namely, faithfulness(信), expressiveness(达) and elegance(雅). His faithfulness means that the translated text should be faithful to the original text, i.e, the version should keep the content or ideas of the original. His expressiveness means that the translated text should be expressive and coherent without anything awkward. In other words, his expressiveness requires that the version should be fluid, smooth, and easy to read and understand. His elegance demands that the translated text should be exquisite and that its style ought to be very graceful.

\subsection{Basic Ways of Menu Translation}

As the two most widely-used translation methods, literal translation and free translation have been argued about since the dawn of the language translation, which are being distinguished by "word-for-word”(literal) and "sense-for-sense"(free) translation.

\subsubsection{Literal Translation}

Literal translation can make the source language and target language use almost the same form to express the same content, and get almost the same effect. So for the translation of dishes, literal translation is desirable and practical method. Translation according to the Main ingredient, seasoning and cooking methods are usually literal translation

There are a variety of selection of ingredients since China enjoys the benefits of great size and rich natural resources, we have a wide choice among them and choose what we like according to the dietary habit of oneself. Besides, there are also a range of cooking skills in different areas in China, such as 煮(boil), 炖(stew), 蒸(steam), 炒(fry), 烧(braise), 烤(roast), 焙(bake), 熏(smoke), 灼 (scald), 爆(quick fry), 卤(marinate), 腌(preserve/salt/pickle) and so on . There is also a wide choice of cutting skill, such as 切片(slice), 切丝(shred), 切丁(dice/cube), 切柳(fillet), 槑碎 (mince), 捣烂(mash) and so on. Examples are as follows:

With Jelly Fungus and Bird's Nest in Honey Soup（银耳燕窝汤）

Stewed Sliced Fish in Wine Sauce（糟溜鱼片)

Steamed Pork with Rice Flour Wrapped in Lotus Leaves（荷叶粉蒸肉）

Fried Spareribs in Sweet Sour Sauce（糖醋排骨）

Quick Fried Mutton with Green Scallion（葱爆羊肉）

Sliced Chicken with Winter Bamboo Shoots (冬笋鸡片)

Diced Chicken with Chili Sauce（宫爆鸡丁）

Chicken Cubes with Almond（杏仁鸡丁）

\subsubsection{Free Translation}

1. Translation according to the shapes or tastes, which is metaphor-loaded. Most of the naming principles for the Chinese cuisine are not confined to the ingredients or cooking skills, but in regards to the taste, shape or color of the dish itself, which may give rise to the possibility to show people's internal meaning and emotions. In this way, metaphor is coming to us. Examples are as follows: 
Fried Mung Bean Noodles with Spicy Minced Pork （蚂蚁上树）

Stewed Snake and Chicken（龙凤会）

Turtle-and-Chick Longevity Soup（龟鹤延年汤）

Stir-fried Pork Lung Slices (夫妻肺片)

Metaphor is for most people a device of the poetic imagination and the rhetorical flourish-a matter of extraordinary rather than ordinary language. Moreover, metaphor is typically viewed as characteristic language alone, a matter of words rather than thought or action. For this reason, most people think they can get along perfectly well without metaphor. We have found on the contrary, that metaphor is pervasive in everyday life, not just in language but also in thought and action. Our ordinary conceptual system, in terms of which we both think and act, is fundamentally metaphorical in nature. (Lakoff \& Johnson, 1980, p.4) ${ }^{[6]}$ Under such trend, the metaphor-loaded food is becoming more and more popular among both Chinese people and foreigners.

2. Translation according to the Historical allusion and Celebrities, which is Culture-loaded. E. Sapir says, "Culture can be explained as what the society does and thinks" (Sapir, 2002, p.180) ${ }^{[9]}$. And the definition given by Kohla is: "Culture refers to the way of life of a certain community, including what people think, say, do and what they have done.” (Zhou Zhipei, 2003, p.478) ${ }^{[4]}$ For some of the Chinese traditional food names or local snacks, they are usually companied by some historical events or cultural background. Therefore, in order to translate them in a much proper or equivalent way, we need to look up in a lot of books or get to know some specialized customs of the local areas in deep sense. Only in this way, can we give the foreign people a deeper understanding for those culture-loaded cuisines. Examples are as follows:

麻婆豆腐一Mape Tofu

(Bean curd in hot Sauce firstly made by Mapo. an ancient Chinese woman in Sichuan province) 叫花鸡一Beggar's Chicken

(Roasted chicken wrapped in lotus leaves and mud, firstly made by a beggar in ancient China)

东坡肉一Dongpo Braised Pork

(Hangzhou's trademark dish. To eat dongpo pork is to begin to understand the role of fat in making meat taste good.The dish is named after revered Song Dynasty poet, artist and calligrapher Su Dongpo)

Historically, as an important part of food culture, Chinese food culture has made great contribution to the world. "There are many people in other countries who don't know the four great inventions, but few people who don’t know Chinese food.”(Yang Naiji, 1993, p.1) ${ }^{[2]}$

\subsubsection{Transliteration}

With the ever-speeding globalization, especially the intensification and deepening of cultural contacts between China and the rest of the world, Chinese culinary art is universally accepted and acclaimed by foreign gourmets. Some traditional Chinese dishes have won great popularity across the globe and their names are familiar to foreign friends. Some were even compiled into English dictionaries. As for those dishes, we can simply translate them by transliteration, such as tofu, wonton, jiaozi, shaomai and chow fan, no one would frown at these names and ask what they are nowadays.

Transliteration has been widely used by our Chinese people to translate those traditional foreign dishes popular in our country, and these transliterated names are acknowledged by us. For example, sandwich is transliterated into “三明治”, hamburger into “汉堡”, pizza into “批萨”, champagne into “香槟”, salad into “沙拉”. All of them are successful transliterations. Similarly, in the Asian world, some delicacies are introduced to the rest of the world with its original name, such as sushi 
（すし, 寿司）, sake (さけ, 日本清酒), kimchi (韩国泡菜), all being widely used in the western world. Thus, it is high time we followed suit by using Chinese pinyin to popularize our Chinese specialties with a sense of pride for being the originator of these delicacies.

\subsection{Translatability of Chinese Cuisine}

Talking about the English translation of Chinese cuisine, we have to mention the term "Translatability". The Dictionary of Translation Studies offers the following definition: translatability is a term used along with its opposite, untranslatability to discuss the extent to which it is possible to translate either individual words and phrases or entire texts from one language to another. Considering translatability on the word level, Peter Newmark points out that: the more universal the sense is, the more likely the transfer. (Peter Newmark, 2001, p.88) ${ }^{[8]}$ That is to say, if the image in the SL (source language) has correspondence in the TL (target language), reproducing is possible. The fact that most of the dish and food names are translatable is easy to understand, because they have a lot in common with the English language and food culture. The cultural-loaded dish and food names which are absolutely unique to Chinese language and culture are, on the other hand, extremely difficult or even impossible to translate. There are simply too many so-called unbridgeable differences, in these cases, between the Chinese and English languages and cultures. In this case, zero translation, which consists of transliteration and transference can be employed. People search for this areas list their reasons: firstly, target readers are curious about foreign culture and that is why they choose to read translated work. So, it is necessary to introduce alien culture to them. Secondly, translator should bear it in mind that readers possess the needed intelligence and imagination to understand the heterogeneity in other cultures. Thirdly, the aim of translating is to promote cultural exchange, and translation history has proved that it can enrich the target language and culture. Lastly, absolute fidelity doesn't exist unless translation conveys all the phenomena of the SL. (Guo Jianzhong, 2000, p.279) ${ }^{[1]}$

\section{Translation of Metaphor-loaded and Culture-loaded Cuisine}

Translation is defined as "the act or process of rendering what is expressed in one language or set of symbols by means of another language or set of symbols" in Encyclopedia Britannica. (Mary Snell-Hornby, 2002, p.39) ${ }^{[10]}$ In order to get to know the actual meaning of metaphors to an equivalent identity, we must take cultures into consideration.

Compared with western food names, Chinese dish names are quite unique because there are plenty of metaphor-loaded food names which are characteristically based on the cultural factors. It is especially the case in China. As a country enjoying thousands of years of culture with much emphasis on food, China's various dish names not only reflect its amazing variety of ingredients, cooking skills, seasonings, and ways of cutting, but also deliver much artistic values and cultural elements, including folklores, legends, poetic images, etc.

\subsection{The Functions of Metaphor and Culture in Chinese Menu}

"Food for humanity has, over the centuries, been an important determinant in the rise and endurance of nations.(C. Carole and Penny V. E., 1979, p.2) ${ }^{[5]}$ A self-descriptive dish name normally informs readers of the ingredients, cooking methods, flavor and so on through the name itself so that the information function is realized. However, as for a metaphor-loaded dish name, the information function here usually is blank or rather weak. For instance, readers or listeners may be baffled with dish names like “龙凤呈祥” (Loog and Feng bring prosperity) because they can 
neither know about the material of the dish nor the flavor of it. From the information respect, it could only make sense to those who have tasted it before. Generally speaking, it cannot be denied that metaphor-loaded dish names have some drawbacks in information function. However, we need to note that other functions like artistic function, social-cultural function and advertising function are highlighted in the metaphor-loaded food names.

\subsubsection{Artistic Function}

Chinese culinary art, as an indispensable treasure in Chinese culture, inevitably incorporates various cultural elements, and as an envoy of friendship in international exchanges, it plays a role of its own in promoting Chinese culture. Thus, "Chinese dish translation should serve to promote Chinese traditional culture and give publicity to the culinary culture and traditions of China as much as possible”. If we say Chinese food is work of art then, the metaphor-loaded food names could be the art of art for its artistic value, which is mainly displayed in the following aspects: vividness, novelty and elegance. Since popular images are applied in the food names, which often ignite people's associations, the food names that would have been insipid. For example, dish names such as “白鸟朝风”, “出水芙蓉鸭”, “孔雀开屏” and “苏堤春晓” are associated with lovely animals, beautiful flowers and sceneries, which induce readers to imagine, to acquire an enjoyment. Novelty is another draw of metaphor-loaded food names. Metaphors full of wits and humor often add colors to a dish that would have been very common. For instance, “蚂蚁上树”, a well-known dish, is to compare the minced pork with "ants" and vermicelli with "trees", creating a novel image of ants climbing up the trees. And in the dish name “乌云托月”(the moon rising from black clouds), laver is compared to "dark clouds" while poached eggs to " the moon". Such a fancy food name tends to catch dinners' curiosity immediately and then make them smile when the dish is laid before them. Though there may be nothing remarkable in the dish itself, the fantastic name which refreshes people is another kind of enjoyment.

\subsubsection{Social-cultural Function}

There is often more to the name of a Chinese dish. Chinese metaphor-loaded dish names distinguish themselves from that of other countries for its national characteristics. Generally, there is a subject or theme for a Chinese feast on which all the dish names could center, such as cultural elements like “福，禄，寿，喜，财，吉”. Dish names like “姻缘美满”“比翼双飞” and “百年好 合” are to convey best wishes for the people and wish them a happy and sweet marriage or live; “沉 鱼落雁” connotes both beautiful and charming while “发财好市”, “牛市大吉”, “金牌鸿运”, “金钱 滚滚” and “富贵有余”wish people make fortune and live a well-to-do life. Moreover, Chinese dish names are designed according to the status of the guests. Palace dishes are named to wish the rulers good luck and long life, such as the famous dishes in Manchu and Han Banquet（满汉全席） “日 月生辉”, “松鹤延年”, “凤凰出世”, “万年长青” and the like. And if the banquet is attended by business men, the dish names would convey best wishes for successful careers, such as “发财好 市”, “金银满地” , “元宝大虾” and so on. Chinese dish names also function as a culture carrier. Plenty of cultural words play a significant role to demonstrate the national features. “龙”, “凤”, “驾 尞”, “佛”, “仙鹤”, “菊花”, “梅花” 和“荷花” frequently appear in Chinese dish names, which are unique to Chinese culture or have rich connotations compared with that of other languages. 


\subsubsection{Advertising Function}

In a sense, a dish name is like an advertisement. For a restaurant, the self-descriptive dish names provide information in a brief way that customers are concerned about, so that they can order according to their preference. Therefore the strength of the self-descriptive dish names is to pinpoint the features of a dish in brief and explicit language. However, as everything has its two sides, this also brings about its weakness because direct and plain language seems to be very insipid and often fail to invite customers to consume. It is different with metaphor-loaded food names whose strength lies in drawing customers' eyeballs and attract them to consume. First of all, the beautiful language of metaphor is always delightful and capable of catching customers' interest. Furthermore the lively images that the dish names involve can either sparkle rich imagination or strong curiosity for customers may wonder what the dish with such a beautiful name is made of and how it tastes. Driven by the imagination or curiosity, it is very likely for customers to have a try. Therefore, metaphor-loaded dish names appeal more to customers for its effects on their psychology, particularly for Chinese people who regard eating as a kind of cultural enjoyment. From attracting customers' interest to calling upon them to react in the way intended, metaphor- loaded food names embody the function of advertisement. For a restaurant, the foremost purpose is its commercial interests. That is why Chinese restaurants will spend so much time and energy in naming their dishes.

\subsection{The Linguistic Features of Metaphor-loaded and Cultre-loaded Food Names}

As a rhetorical device, metaphor in Chinese food names is used to describe the shape or appearance of the dish so as to capture the attention of customers. Therefore, it has distinguished features in language.

First of all, four-character expressions are frequently used in order to pursuit symmetry, which is widely considered as the principle of beauty in China. The balanced number of syllables in a word or a phrase is preferred in Chinese. The Chinese language is composed of many four-character expressions formed by two disyllable words, creating the effect of neat structure, compact meaning and artistic value. It is also true of the metaphor-loaded food names, which include many idioms and phrases that emphasize the even effect, such as “白鸟朝凤”, “松鹤延年”, “金狮绣球” and “游 龙戏风”.

Secondly, words or idioms related to the six themes of “福, 禄, 寿, 喜, 财, 吉” are frequently used. For example, “百花”, “牡丹” and “玉”are images of “福”(happiness); “五子登科”, “带子上 朝”, “鲤跃龙门” are about “禄”(fame and success); ”龟”, “鹤”, and “菊” are related to “寿”(longevity); “喜鹊”, “满堂红”and “开门红”are images of “喜”; “金钱”, “元宝”, “翡翠” and “珍珠” are about “财” (wealth); “龙”, “凤”, “狮” are related to “吉”. Generally speaking, shrimp gelatin is often compared to “百花”(flowers) ; chicken is compared to “凤”(Feng); egg white is associated with “芙蓉” (lotus flower) ; vegetables are likened to “翡翠” either for their shapes or color or luster.

Thirdly, although there are a lot of translation methods associated with the shape, color, taste, smell, metaphor and culture, they may not fit every dish name. For instance, what would be the translation of “狗不理包子” ? Translated literally, it would be Dog-Won't-Pay- Attention and nobody will try to taste it since the name reveals that it is so bad that even dogs won't pay attention to it. If translated liberally, it would be steamed stuffed bun which cannot stand out among other buns and could hardly arouse anyone's interest. And if translated by transliteration, it would be Goubili Baozi, which conveys no meaning to foreigners who are not familiar with the delicacy. In 
this situation, we should exert ourselves to put forward some creative versions. Two successful versions are "Dog-Won't-Leave" and "Go-Believe". "Dog-Won't-Leave” leaves us an image that dog won't leave the buns even though his master orders him to go forward since these buns are so aromatic and tasty. "Go-Believe" is also a good translation because it not only sounds similar to the Chinese name “狗不理”, but shows the confidence of the seller in this product: You can just Go and taste it, then you'll Believe the good taste. Imagine that you are a foreigner and see the two types of names, which one would you prefer?

\subsection{The Cultural Connotations of Metaphors in Chinese Menu}

Chinese Cuisine translation is the process of inter-lingual transformation for semantic equivalence in the specific area of menu and terms in culinary culture. (J. C. Catford, 965, p.39) ${ }^{[7]}$ Since metaphors in Chinese menu convey rich connotations which reflect Chinese ideology, ethnic view, aesthetic value and traditional culture. The glamorous dish names have became an important part of the dish and the epitome of Chinese culture. Therefore without fully understanding the cultural implications behind the food names one can not enjoy Chinese foods completely. Since Chinese people tend to view eating as a kind of social activity, particularly in the banquet or traditional festivals, metaphor-loaded dish names convey auspicious meanings are very popular in China.

\section{Principles for the Translation of Metaphor-loaded and Culture-loaded Cuisine}

As Chinese cuisine consists of innumerable dishes and the dish names are in such a great variety and of so many different styles, no consensus has already been achieved in China on the principles regarding the translation of Chinese dishes. But after reading various articles on this subject, I suggest the following four principles to be paid attention to when conducting dish name translation.

\subsection{Principle of Understandability}

Since the rendering of Chinese dishes are aimed at getting foreigners understand about the dishes, about the main ingredients and methods of preparation, it's our first priority to guarantee the understandability when we are doing dish name translation. What's more, it is a necessity for us to highlight brevity and simplicity in translation, that is, to keep to the ingredients and cooking method of the dish instead of all the elements included in the dish name, to avoid redundancy and complication. Theoretically speaking, such a principle requires that "reproducing the original cultural flavors must be on a level with the readers' capacity of endurance." The translated version will devalue the Chinese menus itself if the readers fail to understand the translations. In translating Chinese menus, on the one hand, we must convey the meanings of those menus; on the other hand, we must take into account the acceptability of TL readers, both linguistically and culturally. In effect, this refers to the fact that the referential meaning and connotative meaning should be in agreement in intercultural translation. If the referential meaning is conveyed in translating, its connotative meaning must be conveyed or understood at the same time. Of however the TL readers fail to comprehend or imagine the connotative meanings, or even worse, if the two kinds of meanings are contradictory to each other, the cultural conflicts may arise. For example, in Chinese dishes to make good wishes, we invent names such as “龙凤配” “二龙戏珠”. If they are translated into “Dragon matching Phoenix" and "Double dragons Playing with a pearl”, they can't well convey the connotation of these names, partly because it is puzzling to the foreigners. So we must shift them and translate them into "Fish and chicken" and "Two fish and one coconut" respectively. The latter translations are better ones so far as the connotation and readers' acceptability are concerned. This 
example further confirms that which specific translation principle is adopted in translating must also depend on the principle of readers' acceptability.

\subsection{Principle of Semantic Faithfulness}

Faithfulness is an important question of the principle of translation. All theorists, both in China and abroad, maintain that translation should be faithful to the original. In China, when people talk of the translation principle or criterion, it seems that no one can escape from the reference to Yan Fu's triple-element principle, that is, faithfulness, expressiveness and elegance. Similarly, in the west, many translations and translation theorists such as Horace, Dryden and Nida, to name a few, also advocate the faithfulness or fidelity of translation. Nida's definition of translation can clearly exemplify this: "Translation consists in reproducing in the receptor language the closest natural equivalent of the source language first in terms of meaning and secondly in terms of style." Although these propositions are diversified, they influence and complement one another and increasingly aim at the "ideal" or "perfect". They may weigh on one side or the other, but the key and central idea is basically the same, that is, the translated versions should express the original in a faithful way, whether in meaning, style or central thought, etc.

The same is true of translating the Chinese menus into English, that is, we should also emphasize the principle of faithfulness. But for Chinese menus, we should mainly emphasize the faithfulness to the original terms in meanings. The meaning here refers to the literal meaning or image meaning and implied meaning (e.g. cultural connotations). These three meanings may not exist in the original words or expressions at the same time. Because any two languages and cultures are not identical, it is often impossible to completely convey the three meanings into the target language. As contradictions arise between literal meanings or image meaning and the implied meaning as caused by cultural differences, literal meaning or image meaning should give priority to implied meaning, which is the most crucial and important in translating the Chinese menus. “霸王别姬” in Chinese, for example, should be translated into "Broiled Chicken Cutlets with Tunic" instead of “The King Saying Goodbye to His Concubine”, “狮子头” should be rendered into “pork balls” rather than "Lion's head" . So the primary concern of the translator should be the meaning of the original message.

\subsection{Principle of Culture-based}

As cross-cultural communications becomes unprecedentedly popular nowadays and due to the differences in historical backgrounds, geographic locations, social customs, religious beliefs, etc., different countries have different cultures, hindering people from understanding each other. Translation obstacles naturally exist because of language barriers and cognitive barriers. In cross-cultural communication avoiding cultural misunderstanding is one significant principle.

Chinese culinary art, as an indispensable treasure in Chinese culture, inevitably incorporates various cultural elements, and as an envoy of friendship in international exchanges, it plays a role of its own in promoting Chinese culture. Thus, "Chinese dish translation should serve to promote Chinese traditional culture and give publicity to the culinary culture and traditions of China as much as possible". (Zhen Jinhuai, 2004, p.89) ${ }^{[3]}$ In translating Chinese dishes, especially those with profound cultural background or historical elements, introductions to the fascinating stories behind them are necessary. It is needed for foreigners to better understand the dish's origin and the Chinese cuisine as a whole. In the practice of translating dish names, it is a must to help foreign friends to be acquainted with the profound cultural elements and the unique Chinese cultural traits included in the dish names in a more in-depth manner. 


\section{Conclusion}

China, with its deep cultural connotation and constant development of her cuisine, is renowned as the Kingdom of Cooking. Chinese Food has a long history and is famous all over the world. The traditional food of a nation reflects its historical and cultural characteristics. As an old Chinese saying goes that: "People regard food as their prime want, and food should be given the top priority.” From this we know, people regard food as the most important thing. Food culture is an important part of traditional Chinese culture. According to the survey, more than a third of the world's population eats Chinese food. And there is an ever increasing interest in Chinese food around the world. It is very important to translate Chinese cuisine names accurately and vividly. Accurate translation of Chinese dishes into English can make foreign friends better understand the art and cultural connotation of the names of dishes, and at the same time they can taste the unique flavor of Chinese dishes. Good translation of Chinese dishes into English is all the more important for the promotion of the multi-cultural globe and cross-cultural communication.

Translating Chinese dish names is not an easy task in the least, so it requires whole-hearted devotion and the participation of more people in this field. It is expected that more books and articles on this regard will be published, which will help introduce the translation of Chinese Cuisine, especially in the area of its metaphors and cultures.

This essay is a small attempt to the study on the translation of Chinese dish names. To sum up, in terms of translating Chinese dish names into English, it does matter that to reserve the original cultural implications and to help foreigners to appreciate the profound Chinese culinary culture. This essay will be of some help to those people who are interested in translating Chinese dish names into English, and will, to an extent, promote the cross-cultural communication between China and the rest of the world.

\section{Acknowledgements}

I would like to acknowledge and extend my sincere gratitude to my beloved family and my colleagues. Without their support, I could not have come so far.

\section{References}

[1] C. Carole and Penny V. E. Food and Culture. New York : Routledge, 2008.

[2] George Lakoff and Mark Johnsen. Metaphors We Live By. London: The University of Chicago Press, 2003.

[3] J. C. Catford. A Linguistic Theory of Translation. London: Oxford University Press, 1965

[4] Newmark, P. Approaches to Translation. Shanghai: Shanghai Foreign Language Education Press, 2001.

[5] Nord, C. Translating As a Purposeful Activity: Functional-ist Approach Explained [M]. Shanghai: Shanghai ForeignLanguage Education Press, 2001

[6] Reiss,Katharina, Translation Criticism - The Potentials and Limitations, Routledge, New York, 2014, pp .17. $\square$

[7] Sapir E. Language: An Introduction to the Study of Speech. Beijing: Foreign Language Teaching and Research Press, 2002.

[8] khMary Snell Horby. Translation Studies. Shanghai: Shanghai Foreign Language Education Press, 2002. 